Editorial

\title{
Celebrating 50 Years of Neuroscience
}

\section{Introduction}

The field of neuroscience was developed as a separate entity in the 1960s by researchers in departments of anatomy, biochemistry, neurology, physiology, and pharmacology with convergent interests in understanding the structure and function of the brain. This was capped off by the establishment of the Society for Neuroscience (SfN) in 1969, when a group of scientists (Table 1) decided that a multidisciplinary society might nucleate discussion among researchers across scientific specialties, resulting in increased focus on, and understanding of, brain-behavior connections. The SfN founders' stated goals, "to advance understanding of nervous systems and their role in behavior, to promote education in the neurosciences, and to inform the general public on results and implications of current research," remain the focus of SfN today. The newly elected Council wanted to facilitate communication among its disparate members, so in 1971 it held the first annual meeting of the SfN in Washington DC, with 1396 attendees (Fig. 1).

Almost 10 years later in January of 1981, SfN published the first issue of the Journal of Neuroscience to fulfill its mission of communicating neuroscience research broadly. JNeurosci is therefore on the brink of its 40th birthday and is proud to take part in celebrating 50 years of SfN with an issue devoted to looking back at where we were and forward to where we can go in neuroscience. We commissioned articles from scientists who attended the first meeting, who have moved scientific areas covered in that meeting forward, who are working in completely new areas today, and who are currently trainees and have their eyes on the future of neuroscience research. We have also commissioned a photo essay of images that capture the beauty of neurons and show how far we have come in 50 years.

We hope that this collection will inspire you with how much progress has been made and how much promise there is to make additional advances in understanding neurons, brains, and behavior in the next 50 years.
Table 1. Founding members of SfN, 1969

\begin{tabular}{ll}
\hline Edgar A. Bering & Charles U. Lowe \\
A.T. Bever & Louise H. Marshall \\
John M. Brookhart & Neal Miller \\
James H. Brown & Edward R. Perl \\
Robert W. Doty & Alfred Pope \\
Fred Elmadjian & lernon Rowland \\
Daniel X. Freedman & James M. Sprague \\
Ralph Gerard & Eliot Stellar \\
Lore Heinlein & Robert L. Thompson \\
Richard T. Loutit & John E. Wilson \\
\hline
\end{tabular}

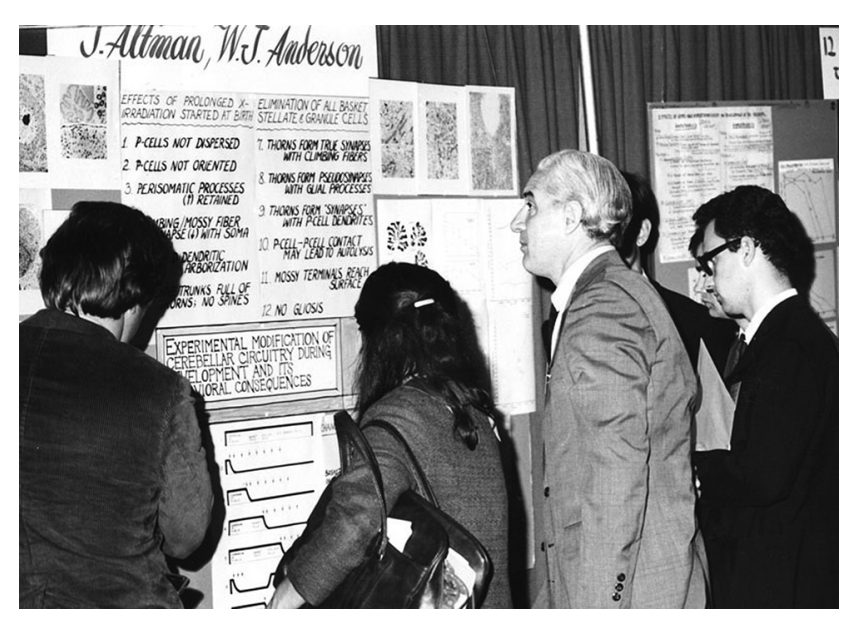

Figure 1. Attendees and poster presenters at the first annual meeting poster floor in Washington, DC. Used with permission from SfN's Archive.

(D) Marina R. Picciotto

EiC, JNeurosci

https://doi.org/10.1523/JNEUROSCI.0712-19.2019 